\title{
SINTESIS SENYAWA N-(2-NITROBENZIL)-1,10 FENANTROLINIUM KLORIDA DARI 2-NITROBENZIL KLORIDA DAN 1,10-FENANTROLIN MONOHIDRAT
}

\section{SYNTHESIS OF N-(2-NITROBENZYL)-1,10-PHENANTROLINIUM CHLORIDE FROM 2-NITROBENZYL CHLORIDE AND 1,10-PHENANTROLINE MONOHIDRATE}

\author{
Artie Noor Pratiwi, Nurkhasanah \\ Fakultas Farmasi, Universitas Ahmad Dahlan \\ Jl Prof. Dr. Soepomo, Janturan, Yogyakarta \\ Email: arttiwi.hadi@gmail.com
}

\begin{abstract}
ABSTRAK
Senyawa N-(2-nitrobenzil)-1,10-fenantrolinium klorida telah disintesis melalui reaksi subtitusi nukleofilik bimolekuler $\left(\mathrm{S}_{\mathrm{N}} 2\right)$ antara senyawa 2-nitrobenzil klorida dengan 1,10fenantrolin monohidrat. Sintesis senyawa dilakukan dengan memvariasikan 2-nitrobenzil klorida terhadap 1,10-fenantrolin monohidrat yakni 1:1, 3:1, 5:1 dan 7:1. Campuran diaduk selama 11 jam. Kemurnian senyawa hasil sintesis ditentukan berdasarkan data jarak lebur dan KLT. Identifikasi struktur senyawa hasil sintesis dilakukan dengan spektrometri UV/Visibel, Inframerah dan GC-MS. Dari hasil sintesis didapatkan senyawa N-(2-nitrobenzil)-1,10fenantrolinium klorida yang berupa padatan amorf berwarna dengan rerata rendemen yang optimal sebesar $37 \% \pm 5 \%$, dan variasi mol 2-nitrobenzil klorida berpengaruh pada jumlah rendemen, rendemen optimal terdapat pada perbandingan mol 1:1.
\end{abstract}

Kata kunci : sintesis organik, 1,10-fenantrolin, antimalaria, 2-nitrobenzil klorida

\begin{abstract}
The compound N-(2-nitrobenzyl)-1,10-phenantrolinium chloride has been synthesized by nucleophilic substitution reaction bimolecular (SN2) between the 2-nitrobenzyl chloride with 1,10-fenantrolin monohydrate. This study is an experimental research of Organic Synthesis. Synthesis is done by varying the compound 2-nitrobenzyl chloride to 1.10 Phenantroline monohydrate ie 1:1, 3:1, 5:1 and 7:1. The purity of the compounds synthesized are determined based on the melting range data and TLC. Identification of the structure of the compounds synthesized done by spectrometry UV/Visible, IR and GC-MS. The results of this research is a colorless amorphous solid from N-(2-nitrobenzyl)-1,10-phenantrolinium chloride with an optimal yield $37 \%+5 \%$ and the variation of mole 2-nitrobenzyl chloride effect on the amount of yield product, there is an optimal yield in the mole ratio of 1:1.
\end{abstract}

Key words : Organic Syntesis Organik, 1,10-phenantroline, antimalarial, 2-nitrobenzyl chloride 


\section{PENDAHULUAN}

Malaria adalah penyakit infeksi yang disebabkan oleh parasit Plasmodium yang hidup dan berkembang biak dalam sel darah merah manusia (WHO, 2013). Kendala dalam pemberantasan tersebut adalah timbulnya kasus resistensi insektisida dan parasit terhadap antimalaria yang tersedia (Wongsrichanalai et al, 2002). Departeman Kesehatan RI (2008) menyatakan kasus resistensi Plasmodium falciparum terhadap klorokuin di Indonesia pertama kali ditemukan di Kalimantan Timur pada tahun 1973. Kejadian ini terus berkembang hingga tahun 1990, dilaporkan terjadi resistensi $P$. falciparum terhadap klorokuin.

Salah satu cara penanganan resistensi melalui sintesis golongan senyawa yang telah dikenal mempunyai aktivitas antimalaria. Antimalaria golongan fenantren adalah halofantrin, senyawa ini telah terbukti memberikan efek yang baik terhadap kasus malaria $P$. falciparum yang resisten terhadap beberapa obat antimalaria (Tjitra et al., 1992). Yapi et al. (2000) dan Mustafa (2000) melalui penelitiannya menemukan bahwa subtitusi atom Nitrogen $(\mathrm{N})$ pada kerangka fenantren pada posisi 1 dan 10 memiliki aktivitas antiplasmodial yang paling baik dengan nilai IC $_{50}$ berkisar 2 uM terhadap strain Plasmodium falcifarum yang resisten klorokuin maupun yang sensitif klorokuin.

Wijayanti, et al. (2006) menemukan substituen N-benzil-1,10-fenantrolin mempunyai aktivitas yang lebih besar dibandingkan dengan N-alkil-1,10fenantrolin. Hadanu et al. (2012) mensubstitusi gugus $\mathrm{NO}_{2}$ pada kerangka utama 1,10- Fenantrolin dengan model senyawa utama 5-nitro-1,10-fenantrolin hidrat. Senyawa ini telah dilakukan subtitusi halogen dan alkana pada atom $\mathrm{N}_{1}$ sehingga membentuk senyawa garam kwartener. Gugus $\mathrm{NO}_{2}$ merupakan gugus yang akan menyebabkan pengurangan negatif muatan bersih pada atom $\mathrm{N}_{1}$ sehingga akan meningkatkan kemampuan senyawa sebagai antiplasmodium (Mustafa et al., 2002). Sintesis dengan mensubtitusikan gugus halogen belum dilakukan Penelitian ini akan melakukan modifikasi dengan substitusi gugus klorida. Penelitian sebelumnya senyawa ini memiliki ketoksikan yang kecil dilihat dari nilai index terapinya dibandingkan substitusi dengan iodida (Wijayanti, 2006). Penelitian ini melakukan sintesis N-(2-nitrobenzil)-1,10-fenantrolinium klorida dari 2-nitrobenzil klorida dan 1,10-fenantrolin monohidrat dengan variasi mol untuk mengetahui pengaruh rendemen terhadap variasi mol.

\section{METODE PENELITIAN}

\section{Alat}

Alat yang digunakan adalah labu alas bulat (LAB) leher tiga (pyrex), termometer (pyrex), pendingin balik (pyrex), pengaduk magnet (pyrex), hot plate (IKA), penangas air, corong buchner (pyrex), pompa vakum, shimadzu FTIR PRESTIGE 21, UV-vis spektrofotemeter UV-1700 PHARMASPEC, dan shimadzu GCMS -QP2010SE, serta alatalat gelas (pyrex).

\section{Bahan}

2-nitrobenzil klorida (Merck), 1,10fenantrolin monohidrat p.a. (Merck), aseton p.a. (Merck), dietil eter p.a. (Merck), diklormetan p.a. (Merck), metanol p.a. (Merck), butanol p.a. (Merck), aqua, etil asetat p.a. (Merck), silica gel.

\section{Jalannya Penelitian}

\section{Sintesis N-(2-nitrobenzil)-1,10- fenantrolinium klorida variasi mol}

Sintesis dilakukan dengan 4 macam kelompok campuran yang terdiri dari perbandingan mol senyawa 2-nitrobenzil klorida (171,58 gram/mol) dan 1,10 fenantrolin monohidrat $(198,24 \mathrm{gram} / \mathrm{mol})$ 1:1, 3:1, 5:1 dan 7:1. Setiap campuran dilarutkan dalam 7,5 mL aseton. Campuran direfluks pada suhu $\pm 55^{\circ} \mathrm{C}$ selama 11 jam 
dengan kecepatan pengadukan $300 \mathrm{rpm}$. bimolekuler $\left(\mathrm{S}_{\mathrm{N}} 2\right)$ seperti tertera pada Senyawa direkristalisasi dengan dietil Gambar 1. Starting material yang digunakan eter:diklormetana (1:1).

\section{Kemurnian senyawa hasil sintesis}

Hasil sintesis diuji titik lebur dengan Melting Point Aparatus dan KLT menggunakan fase gerak n-butanol:asam asetat:air $=2: 2: 6$.

\section{Identifikasi Senyawa Hasil Sintesis}

Hasil sintesis dianalisa keberadaan gugus fungsional dengan FTIR Shimadzu, Spektra UV-Vis dan bobot molekul senyawa dengan MS Shimadzu.

\section{HASIL DAN PEMBAHASAN}

1. Sintesis senyawa $\mathrm{N}-(2$ nitrobenzil) 1,10 fenantrolinium klorida

Senyawa N-(2-nitrobenzil)-1,10 adalah 2-nitrobenzil klorida sebagai substrat yag memiliki leaving groupgugus klorida, sedangkan senyawa 1,10-fenantrolin monohidrat sebagai senyawa nukleofil karena memiliki pasangan elektron bebas pada atom nitrogen.Sintesis dilakukan dengan variasi mol 2-nitrobenzil klorida untuk mengetahui pengaruh variasi terhadap jumlah rendemen. Sintesis dilakukan menggunakan pelarut aseton selama 11 jam dengan suhu $\pm 55^{\circ} \mathrm{C}$ dan pengadukan $300 \mathrm{rpm}$. Hasil reaksi sebelum diisolasi didiamkan pada suhu kamar \pm 6-8 jam untuk memadatkan hasil reaksi yang berupa cairan kental. Rendemen dimurnikan menggunakan diklormetana:dietil eter (1:1) (Hadanu et al., 2012). Gambar produk sebelum dan sesudah pemurnian tertera pada Gambar 2, dan hasil rendemen serta pemurnian tertera pada Tabel I.

fenantrolinium klorida disintesis melalui reaksi yaitu reaksi subtitusi nukleofilik

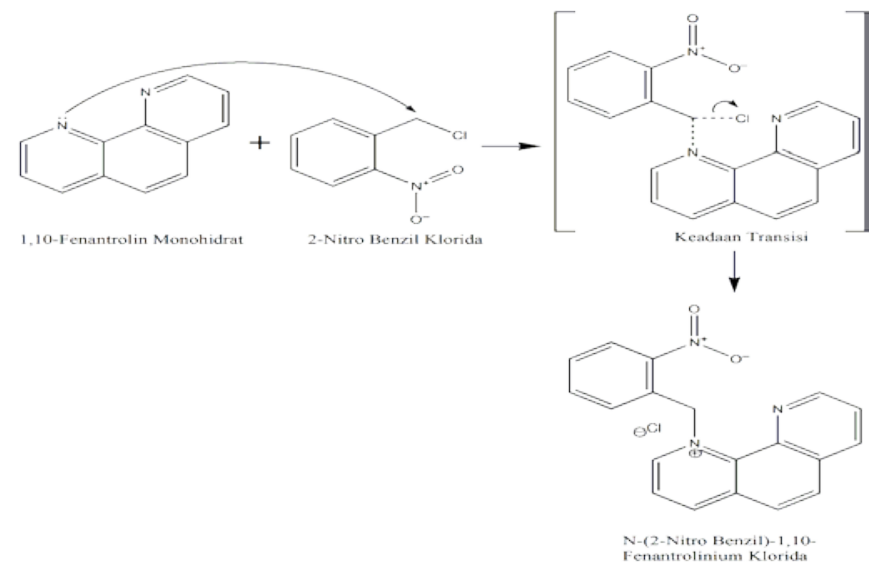

Gambar 1. Mekanisme reaksi sintesis N-(2-nitrobenzil)-1,10-fenantrolinium klorida
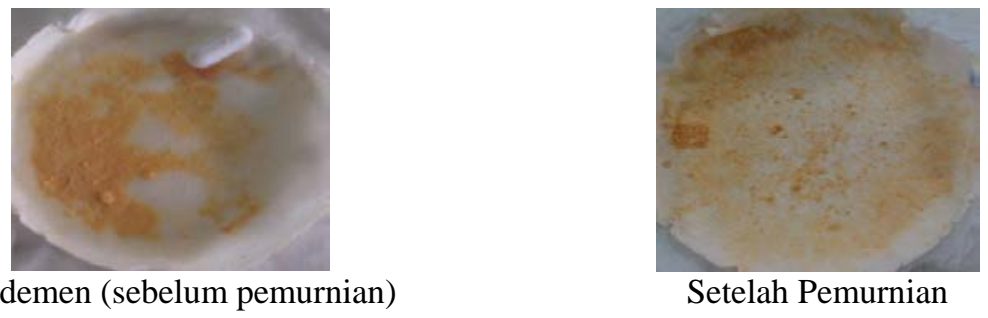

Gambar 2. Senyawa N-(2-nitrobenzil)-1,10-fenantrolinium klorida sebelum dan sesudah pemurnian 
Tabel I. Hasil isolasi, pemurnian, dan besarnya rendemen senyawa 1-N-(2-nitrobenzil)1,10-fenantrolinium klorida

\begin{tabular}{cccc}
\hline Kelompok & Hasil Isolasi (gram) & Rendemen (\%) & Hasil Pemurnian \\
\hline 1 & 0,1302 & 37,00 & 0,1199 \\
2 & 0,1153 & 32,78 & 0,1107 \\
3 & 0,0976 & 27,74 & 0,0923 \\
4 & 0,0773 & $21,98^{*}$ & 0,0712 \\
\hline
\end{tabular}

Keterangan:

Kel 1: perbandingan 2-nitrobenzil klorida:1,10-fenantrolin monohidrat $=1: 1$

Kel 2: perbandingan 2-nitrobenzil klorida:1,10-fenantrolin monohidrat $=3: 1$

Kel 3: perbandingan 2-nitrobenzil klorida:1,10-fenantrolin monohidrat $=5: 1$

Kel 4: perbandingan 2-nitrobenzil klorida:1,10-fenantrolin monohidrat $=7: 1$

Hasil Isolasi, Rendemen dan Pemurnian berasal dari rata-rata 3 data.

*menunjukkan perbedaan signifikan terhadap kelompok 1 (Uji statistik Anova dengan uji lanjutan LSD, $\mathrm{P}=95 \%)$

Hasil ini menunjukkan pada kelompok 1 menghasilkan rendemen paling tinggi dengan rata-rata rendemen $37,00 \%$. Hal ini dapat disebabkan semakin banyaknya substrat 2-nitrobenzil klorida akan menyebabkan suasana reaksi menjadi crowded dan menganggu serangan nukleofilik pada substrat sehingga semakin meningkatnya mol 2-nitrobenzil klorida yang direaksikan rendemen semakin kecil. Hasil ini menggambarkan senyawa 1,10-fenantrolin monohidrat hanya mampu mengikat 1 molekul 2-nitrobenzil klorida pada salah satu atom $\mathrm{N}$ pada stuktur 1,10-fenantrolin monohidrat.

Jumlah rendemen yang kecil dapat disebabkan oleh pengaruh posisi $\mathrm{N}_{1}$ dan $\mathrm{N}_{10}$ pada 1,10-fenantrolin monohidrat yang berdekatan mengakibatkan hambatan sterik sehingga hanya 1 atom $\mathrm{N}$ yang dapat mengikat 2-nitrobenzil klorida. Selain itu, gugus pergi Klorida memiliki kemampuan gugus pergi yang kurang baik dibandingkan halogen lainnya (Fessenden, 1986). Hal ini sesuai dengan hasil penelitian sintesis $\mathrm{N}$-(4nitrobenzil)-1,10-fenantrolinium bromida yang dilakukan pada kondisi yang sama, penelitian tersebut menghasilkan rendemen yang lebih banyak ( $>90 \%)$. Hasil ini juga didukung oleh suhu dan waktu sintesis yang belum optimal menyebabkan reaksi belum berjalan secara optimal.

\section{Kemurnian hasil sintesis}

Kemurnian hasil sintesis dilakukan dengan pengujian Titik Lebur dan Kromatografi Lapis Tipis (KLT). Pengujian titik lebur menggunakan alat Melting Point Apparatus dengan pengaturan suhu teoritis dari senyawa yang hampir sama 223-225 \pm $10^{\circ} \mathrm{C}$ (Hadanu et al., 2012). Hasil uji titik lebur senyawa hasil sintesis terdapat pada Tabel II.

Hasil ini menunjukkan masih terdapat senyawa yang tidak murni, hal ini dapat disebabkan metode pemurnian yang belum optimal. Pengujian kemurnian juga dilakukan dengan metode KLT. KLT menggunakan sistem normal yakni dengan fase gerak BAA (n-Butanol:Asam Asetat:Air) = 2:2:6 dengan fase diam Silika Gel GF 254. Hasil dideteksi menggunakan lampu UV $254 \mathrm{~nm}$. Hasil elusi seperti pada Gambar 3 dibawah.

Tabel II. Hasil uji titik lebur senyawa hasil sintesis

\begin{tabular}{|c|c|c|}
\hline Kelompok & $\begin{array}{c}\text { Jarak Lebur } \\
\left({ }^{\circ} \mathrm{C}\right)\end{array}$ & $\begin{array}{c}\text { Selisih } \\
\text { Jarak Lebur } \\
\left({ }^{\circ} \mathrm{C}\right) \\
\end{array}$ \\
\hline 1 & $188,2-190,1$ & 2 \\
\hline 2 & $194,2-196,2$ & 2 \\
\hline 3 & $195,8-197,6$ & 1,8 \\
\hline 4 & $195,7-197,5$ & 1,8 \\
\hline
\end{tabular}


merupakan perbandingan perbandingan panjangnya jarak elusi senyawa dengan panjang elusi fase gerak. Nilai $R f$ yang sama pada sistem yang sama menunjukkan senyawa memiliki kesamaan sifat dan struktur.

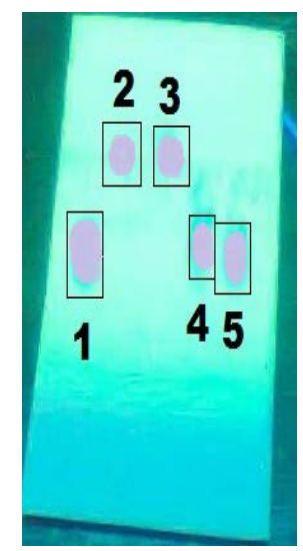

Gambar 3. Hasil uji kemurnian senyawa $\mathrm{N}$-(2 nitrobenzil)-1,10-fenantrolinium klorida secara KLT. FG: n-butanol:asam asetat: air $=2: 2: 6$, FD: Silica gel GF 254, 1: 1,10-fenantrolin monohidrat ; 2: 2-nitrobenzil klorida ; 3: 4-nitrobenzil bromida ; 4: $\mathrm{N}$-(2-nitrobenzil)-1,10-fenantrolinium klorida; 5: $\mathrm{N}-(4-$ nitrobenzil)-1,10-fenantro-

linium bromida, detektor : UV 254

Hasil uji kemurnian dengan KLT menunjukkan kepolaran paling besar ditunjukkan oleh starting material 2nitrobenzil klorida. Hal ini berkebalikan dengan teori yang seharusnya, ini dapat disebabkan terbentuknya fase gerak dua fase yang menyebabkan komposisi n-butanol dengan BJ 0,778-0,782 g/ml (FI IV, 1995) berada paling atas dibandingkan komposisi fase gerak lain dan menyebabkan 2nitrobenzil memiliki nilai $R f$ yang paling besar.

Diketahui bahwa kelarutan 2nitrobenzil klorida larut pada 98\% etanol dan tidak larut pada air (Merck, 2013). Sedangkan, hasil nilai $R f$ produk dengan starting material 1,10-fenantrolin monohidrat yang berdekatan menggambarkan produk memiliki sifat dan struktur yang mirip dengan starting material namun lebih polar karena bentuk produk garam kwartener.

\section{Identifikasi senyawa hasil sintesis}

Identifikasi Struktur Senyawa Hasil Sintesis dilakukan dengan analisa Spektrometri UV-Vis (UV-Vis Spektrofotemeter UV-1700 Pharmaspec), FTIR (Shimadzu FTIR PRESTIGE 21), dan MS (Shimadzu GCMS -QP2010SE). Identifikasi menggunakan Spektrometri UVVis untuk mengetahui panjang gelombang maksimal produk dibandingkan dengan Starting Material. Hasil identifikasi menunjukkan terjadi pergeseran batokromik dengan $\lambda$ maksimal sebesar $271 \mathrm{~nm}$ dari $253,50 \mathrm{~nm}$ dan 263,50 nm. Hal ini membuktikan adanya perpanjangan konjugasi pada produk. Hasil identifikasi Spektrometri UV-Vis ditunjukkan pada Gambar 4.

Identifikasi selanjutnya menggunakan Spektrometri FTIR dengan alat untuk mengetahui keberadaan gugus fungsional pada produk hasil sintesis. Pada identifikasi ini menunjukkan aanya gugus fungsional yang sesuai dengan produk yang ditargetkan, namun terdapat gugus fungsional $\mathrm{OH}$ yang seharusnya tidak ada pada produk. Hal ini juga ditemukan pada penelitian sebalumnya (Hadanu et al., 2012) yang dimungkinkan berasal dari bentuk hidrat pada produk yang berasal dai lingkungan maupun dari starting material 1,10-fenantrolin monohidrat. Spektrum Spektrometri FTIR ditunjukkan oleh Gambar 5.

Identifikasi struktur juga dilakukan dengan spektrometri MS. Analisis ini dilakukan dengan spektrometri terpadu dari GC (Gas Chormatography) yang merupakan analisis untuk memisahkan senyawa yang volatile dengan titik didih dibawah $300^{\circ} \mathrm{C}$. sedangkan MS (Massa Spektrometri) 
merupakan analisis untuk dapat mengetahui bobot molekul dari masing-masing senyawa yang telah dipisahkan dengan GC.

Spektrum Massa di bawah ini menunjukkan fragmen-fragmen yang diduga berasal dari senyawa hasil sintesis. Keberadaan senyawa ditunjukkan adanya fragmen yang menunjukkan massa $353 \mathrm{~m} / \mathrm{e}$ yang berasal dari struktur senyawa hasil sintesis $\left(\mathrm{C}_{19} \mathrm{H}_{14} \mathrm{ClN}_{3} \mathrm{O}_{2}{ }^{+}\right)$dengan isotop klorida 37. Setelah itu, terbentuk fragmen 315 $\mathrm{m} / \mathrm{e}$ akibat lepasnya gugus $\mathrm{H}-\mathrm{Cl}$ yang menyebabkan muatan positif pada gugus $\mathrm{CH}$. Setelah itu, gugus benzil terlepas yang menyebabkan gugus $\mathrm{N}_{1}$ pada struktur dasar 1,10-Fenantrolin bermuatan positif dan membentuk fragmen bermuatan $180 \mathrm{~m} / \mathrm{e}$ dan gugus Benzil dengan muatan fragmen 90 m/e. Pemecahan fragmen senyawa N-(2nitrobenzil)-1,10-fenantrolinium klorida tertera pada Gambar 7.

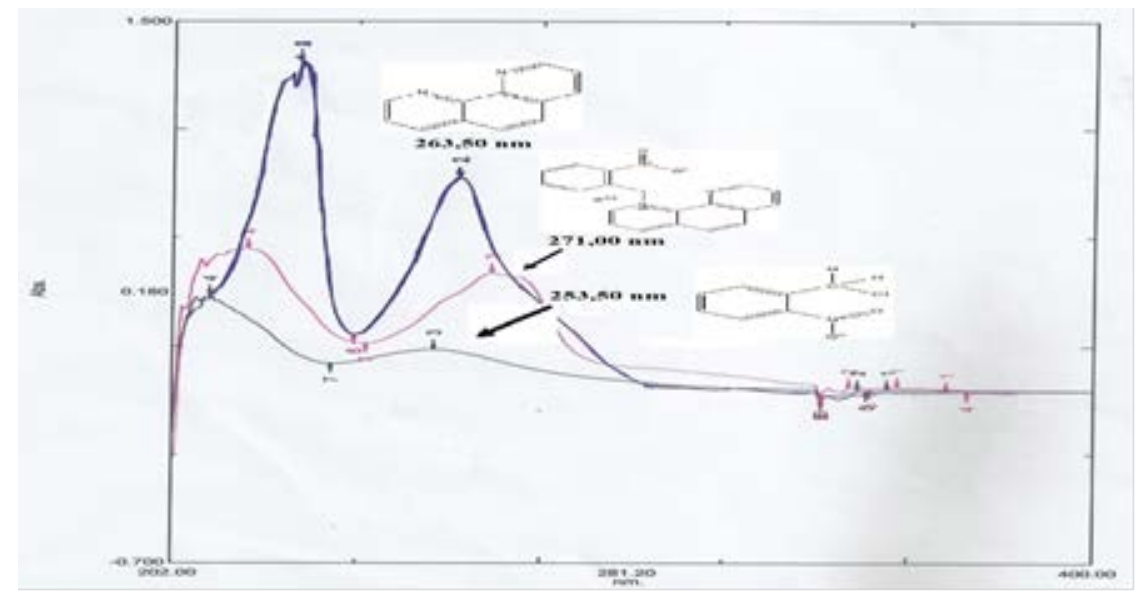

Gambar 4. SpektrumUV produk terhadap Starting Material

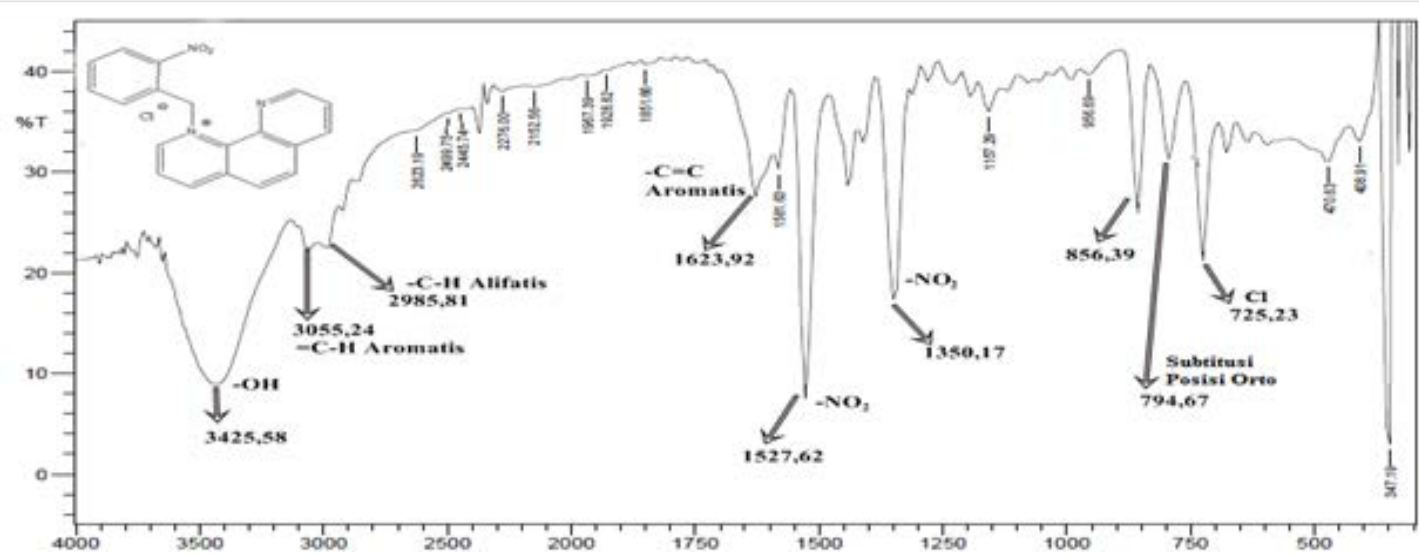

Gambar 5. Spektrum hasil Analisis Spektrometri FTIR Senyawa Hasil Sintesis 

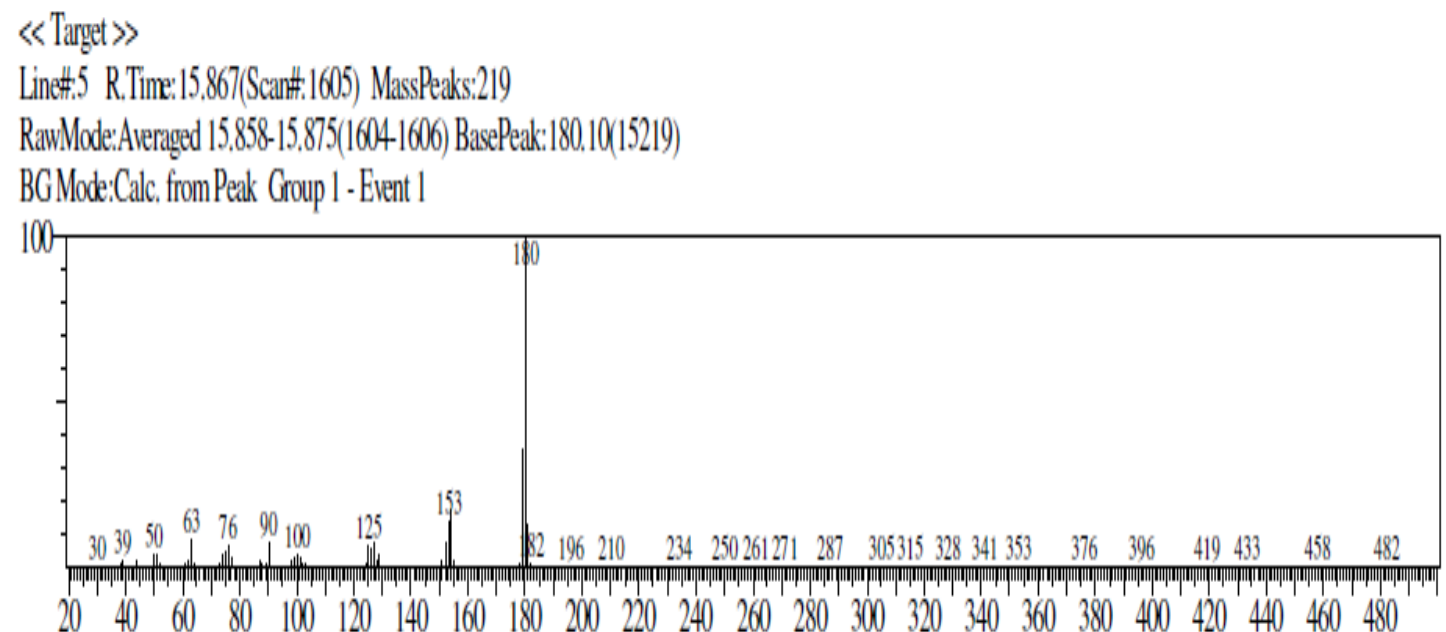

Gambar 6. Spektrum spektrometri MS senyawa hasil sintesis<smiles>O=[N+]([O-])c1ccccc1CN1C=CC=C2C=Cc3cccc1c32</smiles>

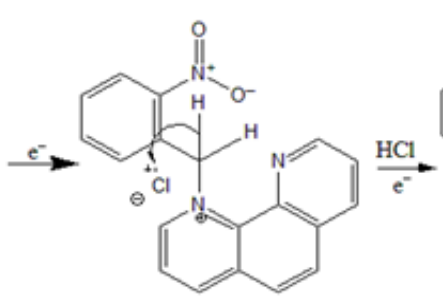

$\mathrm{m} / \mathrm{e}=353$<smiles>O=[N+]([O-])c1ccccc1OCc1cccc2ccc3cccnc3c12</smiles>

$\mathrm{m} / \mathrm{e}=315$<smiles></smiles>

$\mathrm{m} / \mathrm{e}=315$<smiles>c1cnc2c(c1)ccc1cccnc12</smiles>

$\mathrm{m} / \mathrm{e}=180$

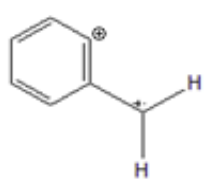

$\mathrm{m} / \mathrm{e}=90$

Gambar 7. Fragmen senyawa hasil sintesis dengan analisis spektrometri massa

\section{KESIMPULAN}

Senyawa

$\mathrm{N}$-(2-nitrobenzil)-1,10fenantrolinium klorida disintesis dari 2nitrobenzil klorida dengan 1,10-fenantrolin monohidrat dengan jumlah rendemen terbanyak pada perbandingan 2-nitrobenzil klorida:1,10-fenantrolin monohidrat (1:3) yakni sebanyak $37,00 \%$. Uji statistik ( $\mathrm{P}=95 \%)$ menunjukkan bahwa terdapat perbedaan yang signifikan antara jumlah rendemen dengan variasi mol 2-nitrobenzil klorida pada kelompok 1 dengan kelompok 4.

\section{UCAPAN TERIMA KASIH}

Peneliti mengucapkan terima kasih kepada Direktorat Jenderal Pendidikan Tinggi yang telah membiayai Penelitian melalui PKM-P. 


\section{DAFTAR PUSTAKA}

Anonim, 1995, Farmakope Indonesia, edisi IV, 1142, Departemen Kesehatan Republik Indonesia, Jakarta.

Depkes. (2008). Pedoman Penatalksanaan Kasus Malaria di Indonesia. jakarta : Direktorat Jenderal Pengendalian Penyakit dan penyehatan Lingkungan.

Fessenden, 1986, Kimia Organik, Jilid 1, Edisi 3, 165-214, Erlangga, Jakarta.

Hadanu, Ruslin., Mastjeh, Sobirin., Jumina, Mustafa., Sholikhah, E.N., Wijayanti, M.A., Syntesis \& Anti Plasmodial Activity Testimg of (1)-N-alkyl-and (1)$N$-Benzil-6-Nitro-1,10-Fenatrilinium Salts as new Potensial anti malaria agent. 2012. Ind. J. Chem. 12(2), 152162.

Husna, Nadia., 2014. Sintesis Senyawa N-(4Nitro Benzil)-1,10-Fenantrolinium Bromida dari 4-Nitro Benzil Bromida dan 1,10-fenantrolin Monohidrat dengan Variasi Mol 1,10-Fenantrolin Monohidrat, Skripsi, Fakultas Farmasi Universitas Ahmad Dahlan, Yogyakarta.

Merck.2013. 2-NitroBenzil Chloride. Germain.

Mustofa, 2000. In Vitro and In Vivo Activity of the Divers of Natural and Synthetic

Antimalarial : Effect of Potentialisator and The Possibility of Mechanism of Action. Disertas., University of Montpellier I. France.
Nuari, Yudha Rizky, 2014. Sintesis Senyawa N-(4-Nitro Benzil) - 1,10-Fenantroli nium Bromida dari 4-Nitro Benzil Bromida dan 1,10-fenantrolin Mono hidrat dengan Variasi Mol 4-Nitro Benzil Bromida, Skripsi, Fakultas Farmasi Universitas Ahmad Dahlan, Yogyakarta.

Tjitra, Emiliara., Oemiyati, Sri., Pribadi, Wita., Romzan, Ali., Arbani, P.R., Reny, marvel., Marwotu, Hariyani., 1992, Pengobatan Malaria Falsiparum Tanpa Komplikasi Dengan Halofantrin di Daerah Resisten Klorokui, badan Peneliti dan Pengembangan Kesehatan Departemen Kesehatan, Bul. Penelit Kes, 20(1) : 2 .

WHO. (2013). Guidelines for the treatment of malaria, 2010. Geneva. 194pp.

Wijayanti, M. A., Sholikhah, E. N., Tahir, I., \& Hadanu, R., 2006, Antiplasmodial activity and acute toxicity of $\mathrm{N}$-alkyl and N-Benzil-1, 10-phenanthroline derivatives in mouse malaria model, Journal of health science, 52(6) : 794799.

Wongsrichanalai, C., Pickard, A. L., WernsdoRfer, W. H., \& Meshnick, S. R., 2002, Epidemiology of drugresistant malaria. The Lancet infectious diseases, 2(4) : 209-218.

Yapi A.D, Mustofa, Valentin A, et al.,2000, New potentialantimalarial agents: synthesis and biologicalactivities of original diaza analogs phenanthrene.Chem Pharm Bull 2000, 48 : 1886-9. 